\title{
Industry 4.0 and service companies: The case of the French postal service
}

\author{
${ }^{1,2}$ Cyrine Selma, ${ }^{1}$ Dalila Tamzalit, ${ }^{1}$ Nasser Mebarki, ${ }^{1}$ Olivier Cardin, \\ ${ }^{2}$ Loic Bruggeman, ${ }^{2}$ Didier Thiériot \\ ${ }^{1}$ LUNAM Université, IUT de Nantes - Université de Nantes, LS2N UMR CNRS 6004 \\ (Laboratoire des Sciences du Numérique de Nantes), \\ 2 avenue du Prof. Jean Rouxel - 44475 Carquefou \\ olivier.cardinels 2 n. fr \\ ${ }^{2}$ La Poste - Direction Technique Branche Services-Courrier-Colis \\ 10 Rue De L'ile Mabon - 44263 Nantes
}

\begin{abstract}
The aim of this article is to overview the transition of smart logistic companies towards the industry 4.0.

Industry 4.0 is a generic concept that subscribes to the idea of a general awareness of the importance of new technologies for manufacturing industry. This reflection aims to conserve and develop a strong and innovative industrial activity to support the modernization of different fields. In the case of high volumes service companies, many reasons have led to this modernization; remarkable increase in the volume of items to deliver, complexity of managing the transportation system and the personnel scheduling, humanization of work conditions, etc. In this work, The French postal service company, La Poste, is given as a particular case of study. La Poste daily treats high volumes of mail and parcel items. In this article, the organization of the French postal service system from the collect to the delivery is explicitly described. A literature review of different concerned research axes is presented. Finally, we present what we think are the future needs for researches in these axes.
\end{abstract}

Keywords: Industry 4.0, high volumes, logistics 4.0, warehousing 4.0, cyberphysical production systems.

\section{Introduction}

Industry 4.0 is defined as the new technological mutation for automatic systems based on the remarkable increase of the speed of information processing, digital storage capacity and massive development of communication systems. This promising revolution's goal is to change the way factories work by the massive introduction of cyberphysical systems known by their capacity to continuously interact with their environment via the coupling of the physical world with information and communication infrastructures. The concept of the factory of the future is based not only on the optimization of the existing solutions but it tends also to integrate real transformations leading to innovative solutions in society, economy, human machine interaction and the manner 
work is planned and operationalized in a production chain. A branch of new technologies are used to facilitate the transition to a more sophisticated manufacturing system also called "smart manufacturing" system, to name a few; the Internet of Things (IoT), cloud computing, big data, Information Technology (IT) and cyber-physical systems.

Today, companies are facing some challenges in the use of smart manufacturing systems. First, companies must be able to handle the pressure of the competitiveness in a global market with a high speed developing technologies. Second, using smart manufacturing systems, all-type companies, regardless to their size, should be dynamically configurable and more able to adapt to the evolution of the global market[1]. Third, reorganizing the production process to enable humans supervise missions and collaborate more easily with machines using more sophisticated interfaces. Forth, promoting a friendlier environment and finally being able to build a cooperative and more mutually beneficial relationship with customers by being a "good neighbor."

Just as all other companies, service companies are facing the same challenges in the transition phase towards the industry 4.0. Such companies operate 24 hours a day, 6 to 7 days a week and being able to adapt their production to a changeable demand in order to meet customer's needs and expectations is a real challenge for service companies nowadays. Furthermore, the high rate of technological evolution and its massive diffusion are considered as permanent sources of innovation in terms of solutions to the actual problems and the organization of the production chain. This leads to a personalized production that meets the needs of each customer instead of the standard one that produces a standard product for everyone.

A company's upmarket strategy is to improve the production chain in order to increase its revenue by increasing products' selling price. This improvement concerns both the nature of the service and the way it's conceived. For the industrial field, the production tool in its ecosystem is an essential component. In fact, within an ecosystem, what really makes the difference is the way the production system works. So far, humans, customers or producers, are the ones who truly drive the growth of the vendor, and being able to provide an ecofriendly workplace fairly close to their living places could make real difference because unlike yesterday, all considerations must be taken into account simultaneously in today's industrial revolution.

The French national postal company, also known as La Poste, is an example of a public service company. Corporatized in 1991, La Poste was a fully state-owned company. It was only in 2010 after the full liberalization of the French market that La Poste has become a public limited company fully owned by the French state. Postal services can be divided into two main activities: parcel and mail delivery. Even if similarities exist, the volume of mail that needs to be handled by postal services coupled to the huge number of delivery destinations make a great difference between these activities. In order to narrow the field of research of this article, only mail delivery activity is considered.

As a matter of fact, we first describe, based on the example of the French postal system, the whole postal process from collection to delivery. Then, we overview research efforts directly related to mail operations around the world. Finally, some research challenges for the application of industry 4.0 in a postal service are highlighted in section 4 . 


\section{Organization of French postal services from the collect to the delivery of mail items}

Postal service network is the system concerned with the transfer of postal goods from the consignors to the receivers. In order to simplify the study of such complex system, postal service network system is divided into multiple interdependent subsystems (collection, transportation, sorting and delivery). In this section different steps of mail transfer from the collect to the delivery are explained in the case of the French postal service network.

The postal service process starts with the collection of goods by postmen from different mailboxes, post offices and business customers in different locations. Business customers also have the possibility to hand over their mail directly to a mail preparation center or to a mail sorting center also known as Mail Industrial Platforms (MIP). In the collection phase, time constraints must be respected in order to ensure the expected quality of service.

These goods are then shipped to a Mail Delivery Center (Figure 1) which exists in a number of several thousand all over the country. In the departure phase, the MDC has a unique mission which consists in collecting mails and shipping them to the Mail Preparation Center (MPC). Neither preparation nor control of mail flows is part of the missions assigned to MDC.

After the transportation of goods to the MPC, goods are sorted for the first time. Mails are separated from parcels in order to be shipped to the adequate MIP. In the preparation phase, mails are primarily sorted, they are separated by destination, format (small, big or out of format) and by shipment quality (delivery day D+1, D+2, D+4 or $\mathrm{D}+7)$. The principal mission of MPC in the departure phase is the preparation of mails and their transportation to the MIP. MPC exist in a number of several hundred all over France.

In MIP, mail items are sorted according to their delivery date: standard mails $(\mathrm{D}+4 / 7)$ for example are sorted only the day before their delivery day. Otherwise, delivery offices, which generally have small warehouses, would be overflown.

More than $90 \%$ of mail items are mechanized (sorted by machines) in MIP, and more than $50 \%$ are finely sorted and sequenced in the delivery order using four types of machines: Preparatory sorting machine MTP, small format mail sorting machine MTIPF, big format mail sorting machine MTIGF and delivery sequence sorting machine TTF (Figure 2). All machines are equipped with an optical character reader capable of reading online handwritten addresses in postal mails. In case of a non-recognition of the address, the machine sends in real-time a picture of the address to a local video-code room where the address is verified by humans and sent to the system after being recognized.

Inside the mail sorting center, mail sorting process is programmed day per day and it depends on volume and type of mail flows. After the arrival of mail items by trucks, the first step is to dispatch them by separating small format from big format's containers. For small format mails, the stamp on mail letters must be verified using the MTP (if it was not done in the mail preparation center), then all small format mails are 
stocked according to their sorting plan not far from MTIPFs. Big format mail letters are also stocked according to their sorting plan next to MTIGFs and manual sorted mails are shipped to the manual workspace. After the sorting process, sorted mail items are transported using conveyers to the departure station where they will be transported using different sized trucks to a MPC or MDC.

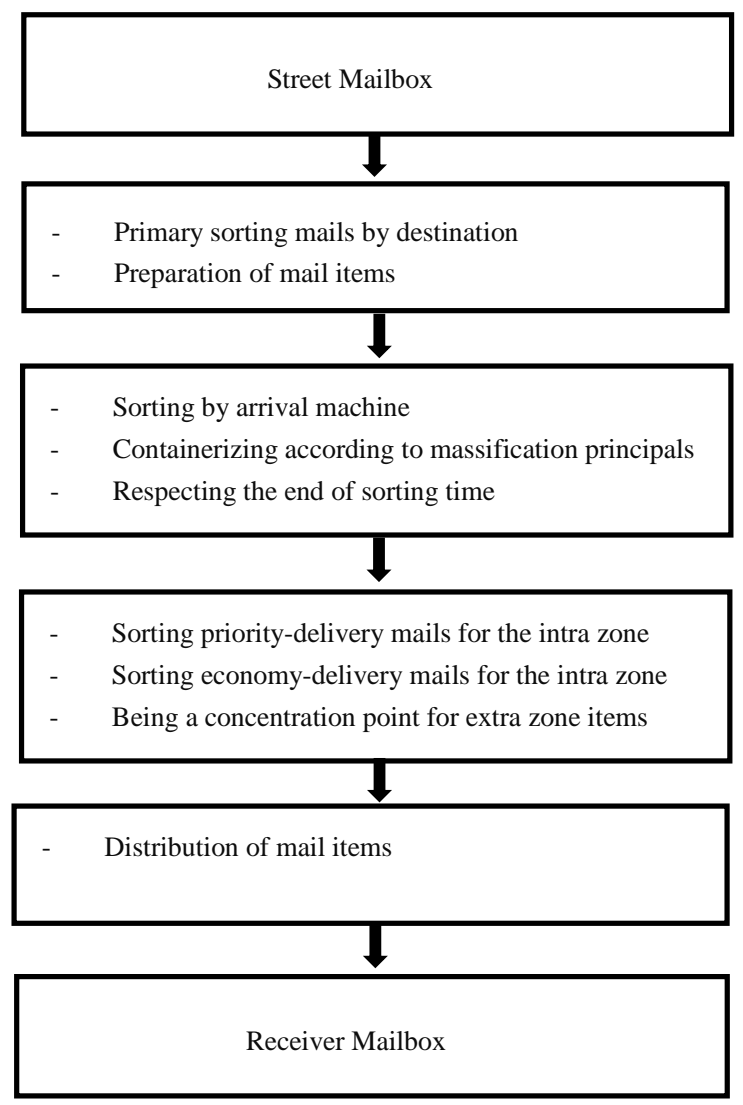

MPC or MDC

Departure MIP

Arrival MIP

Figure 1 Industrial process of postal mail 


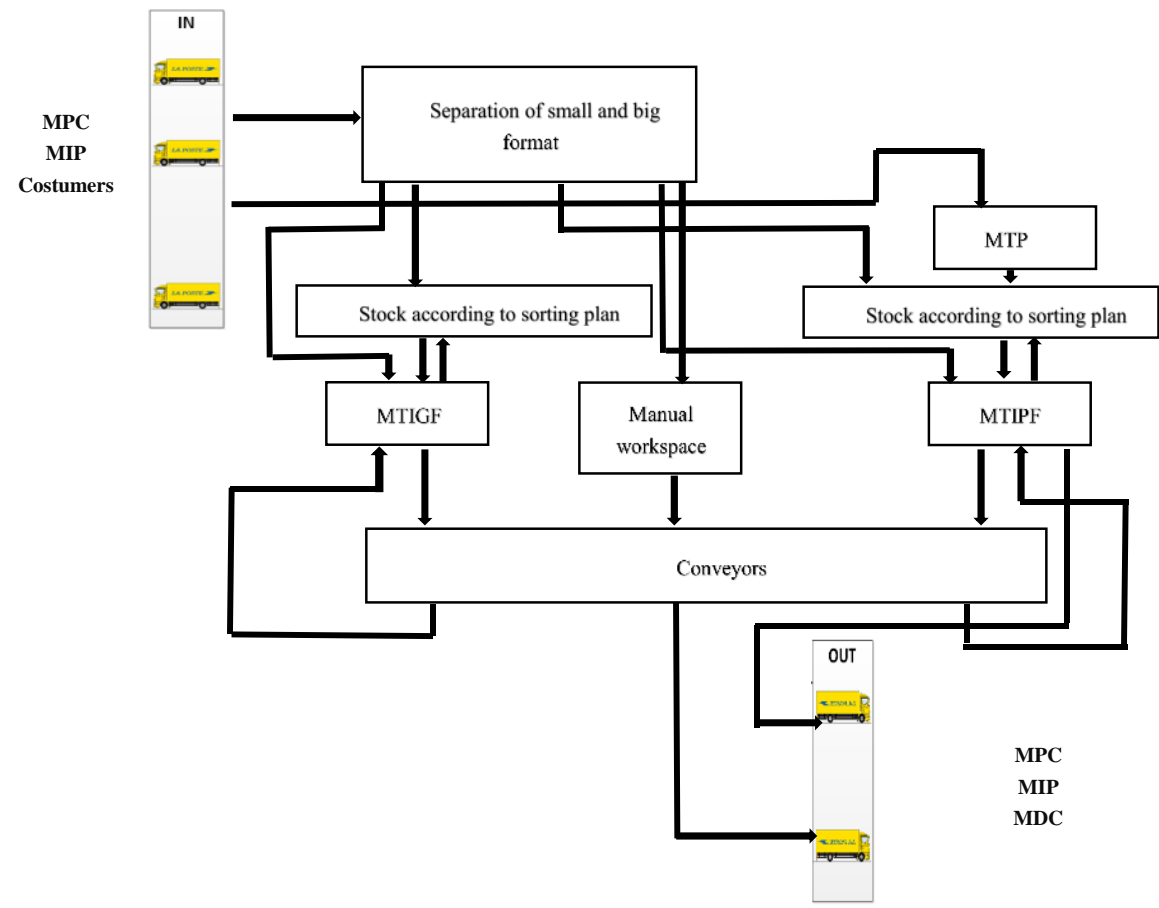

Figure 2 Journey of a mail letter in the MIP

In order to transport different postal items from one postal facility to another, La Poste uses different forms of transport, namely road, rail and air transport. Airplanes are only used for priority items and international destination including overseas departments and Corsica. In 2012, more than $91 \%$ of postal items were transported using trucks. After being sorted in the MIP, mail items are shipped to a MPC which will be in charge of mail dispersion. MPC also represent convenient nodes in the global postal network since they allow the optimization of transport of mail and parcel items between MPC and MDC (Figure 2).

La Poste delivery services are ensured 24 hours a day, six days per week, from Monday to Saturday.

\section{A literature review of different axes of research on postal industry}

Postal mail service networks are facing real challenges today; a falling demand accompanied by an increasing number of competitors in a global developed market full of new communication technologies like Facebook, SMSs, e-mails, fax, etc. Research fields that could help Postal mail service networks to improve their efficiency and to 
stand out in such a crowded competitive market are basically grouped into three different fields; the transportation field including the collect and delivery, sorting field including the recognition of handwritten characters and staff-scheduling field.

Published papers related to the mail service industry in the previously cited fields are gathered here.

\subsection{Transportation}

In order to satisfy the postal services customers' demand on having an on-time delivery with paying the lowest possible cost, transport field is where to begin. Transportation cost is an important part of the total cost of mail service, it includes different costs like vehicle and fuel costs, labor of the driver, toll roads cost, repairs cost, etc. Many studies in the last decades have focused on ameliorating transport systems and reducing its cost in both public and private sectors using different methods. One of these methods is based on minimizing the distance driven by postal vehicles and reducing the number of these vehicles using a model based on relocating distribution centers in order to optimize the distance between different nodes in the postal service network [2].

Moreover, some of the other issues found in the literature about transportation in postal networks are finding the optimum path for deliveries and reducing the costs related to it, like the fuel and vehicle costs [3, 4], transportation planning problems [5, 6], last mile delivery problems and improvement of collection flows while taking into account contractors time obligations [7].

Ant colony algorithm is used for solving a mathematical model for the improvement of collection flows. The algorithm can basically be summarized in four points; first, the first customer to be visited is randomly selected, then the sequence of all customers to be visited is determined based on some probability equation. The second point is to determine each vehicle tour, i.e., the sequence of customer sites visited by one vehicle. The third point is the calculation of the total cost of a vehicle tour and finally, the fourth point is the determination and application of local improvements of the total cost. The last mile delivery problem was also discussed in [8-10].

\subsection{Mail sorting}

The procedure of transferring the mail from the consignor to the receiver consists also of the sorting process in sorting centers. This process kept unchanged for decades. The considerable increase in the volume of magazines, catalogs, parcels and other mail items make impossible to keep sorting manually in postal sorting centers.

One of the issues of the conception of fully automatic sorting machines is the recognition of handwritten postal codes. This challenging problem is an active research topic where the possibility of making an automated system for the recognition of different styles and types of handwritten postal addresses is discussed. In [11], the authors introduced a heuristic algorithm for the segmentation of handwritten postal codes based on two passes; the first pass consists of extracting the fragments of an image and the second pass, of removing the noise, separating the touching patterns and reassembling 
fragments of a broken pattern. This method was proved to correctly segment more than $90 \%$ of Canadian postal codes and could be used with other countries postal codes.

Ciresan et al. [12] have used a Neural Network algorithm with multi-layer perceptrons and numerous hidden layers with many neurons in each layer. This algorithm reached one of the highest rates in the recognition of handwritten characters of $99.65 \%$.

Another algorithm by Niu et al. [13] is considered also one of the best recognition algorithms with a rate of $99.81 \%$. The authors used a hybrid model with the combination of the advantages of the two most successful algorithms ever used for the recognition of handwritten characters: Support Vector Machine (SVM) classifier and Conventional Neural Network (CNN) classifier. The architecture of the algorithm is composed of a 5-layer CNN model where the last output layer is an SVM classifier.

A recent study used an adaptive Q-learning deep belief network (Q-ADBN) algorithm for the recognition of handwritten digits in two global steps, first the extraction of written digits' key features by applying a deep-learning method based on adaptive deep auto-encoder (ADAE) then an algorithm based on Q-learning is applied for decision-making. Other recognition techniques have been discussed in [15-17].

\subsection{Resource planning}

In a service based company like La Poste, the transformation process involves many operations like transportation, sorting mails and delivery. All these operations necessitate a certain level of intervention of human resources. In this context, staff planning problems are one of the most important concerns of service companies. Having a special work time of 24 hours a day and being forced to balance between low and highcharged work periods service companies can face real problems under the use of a poor personnel scheduling. Numerous authors have discussed multiple solutions on how to optimize workforces' operations under different parameters for different type of companies, but only a few discussed it for the case of public postal companies.

In [18] authors addressed the problems of workforces oversupply including full-time and part-time employees. An integrated full-scale linear model was proposed for reducing workforce's size and optimizing their schedules with satisfying the daily demand of employees in postal facilities. The model is focused on the minimization of an objective function depending on total weekly cost parameters of workforces and takes into account different constrains like the number of full-time and part-time employees needed to cover different work operations at different periods of a day including lunch time and the minimization of the number of part-time employees. The objective function was solved using CPLEX and an optimal solution was obtained. The same shift scheduling problem is discussed in [19-21].

Another work in [22] where authors discuss a lot sizing production plan and the minimization of the cost of human resources needed to cover the whole process of production. The problem was modeled using a mixed integer linear model. Optimum solutions are obtained after the application of a branch-and-bound algorithm on different scenarios. 
Workforce scheduling has also been discussed in [23] in order to resolve a personnel planning problem for mail distribution in the United States Postal Service. A generalizable model was constructed for daily work planning where input parameters needed to generate the schedule of a day are only the mail volume and the employee's availability.

\section{$4 \quad$ Industry 4.0 opportunities in mail delivery}

The previous section showed that the research fields explored in mail collection, sorting and delivery are not that vast. Obviously, this industry benefited from other research fields (artificial intelligence, operational research, lean organizations, etc.), but the specificity of such industry was not extensively studied. This section intends to introduce numbers of research challenges that current industry might have to face in order to enhance its efficiency in the next few years.

\subsection{Transportation: towards logistics 4.0}

The transportation sector has been changing rapidly since the wide spread of new information technologies (Industrial Internet of Things among others) and the evolution of e-commerce. This means a continuous growth in the volume of parcels that will be mixed with mail for the distribution. New solutions must address the needs of a flexible system that is able to deal with a high dynamic market with an accommodate growth of items volume, fluctuations of demand and evolution of technologies.

One of the trending solutions for same-day delivery is using drones. They are considered more efficient to deliver parcels or mail items in rural areas, as driving long distances to rural areas is generally very costly and time consuming. Without drones, it becomes mostly impossible to deliver items without making a delay. The short range of drones, the need for high delivery rate and the need for extreme safety leads to the problematic of fleet coordination of multi-modal vehicles (aerial drones, street drones, delivery trucks, etc.) in an open space. Such solutions start to be implemented for military or humanitarian operations [24] but they need to be adapted to be operational in a city environment.

Moreover, innovative IoT technologies make it simpler to couple different objects and sensors. In particular, auto-ID technologies [25] shall be used to detect the presence of an item while being treated. Coupled to a cloud interface, it would then be possible to access the full history of the item, its properties, its current status and its final destination. This could make it possible to enhance customers' relationship with the items, by individually remote controlling the sorting and delivery processes of an item.

Other solutions require a total connectivity and coordination between warehouse and transportation management systems[26]. As an example, connected transport systems will be able to communicate with each other and with warehouses in order to prevent delivery date delays and to optimize the same-day delivery process. 


\subsection{Mail sorting: towards warehousing 4.0}

Industry 4.0 is the response to numerous simultaneous transitions: energetic, ecologic, numeric and societal. All these transitions need new technologies for facing challenges for both continuous and long-term development.

In this context, it is mandatory to adapt the sorting activity control of the warehouses in order to be flexible enough to use this connectivity to the logistic network [26]. The difficulty is to cope with the many disturbances which occur on this type of system (unpredictable demand, weather conditions, etc.) while taking into account the physical constraints (storage sizes, priority of the delivery, etc.). One way to integrate these constraints is to add intelligence to all the logistic devices (machines, robots, storage, etc.) but also as close as possible to the items, and making it intelligent products able to integrate the decision making process of the platforms [27, 28]. These technologies could also ensure a precise traceability of different operations during the whole lifecycle of a product.

Future sorting centers should be fairly automated and equipped with collaborative robots in order to free human operators from painful and repetitive tasks, in this way they can put their cognitive functions at the service of quality, innovation and deployment of agile changes. This agility is meant to enhance the ability of the systems to sort more efficiently multiple formats and contents of the mail. Indeed, getting millions of post items sorted and prepared to delivery on time six days out of seven currently requires different types of machines and some manual sorting. The notions of scalability and re-configurability are also key factors for systems submitted to such volatility [29].

Finally, automated storage/retrieval systems connected with intelligent products might lead to the definition of storage policies able to enhance the global productivity of the centers.

\subsection{Resource planning: towards cyber-physical production systems}

Working in postal service industry includes a lot of manual work. Poor staff-scheduling can lead to considerable losses. The evolution towards a full automatization of the sorting process leads to a loss of personnel working with manual operations, which might significantly reduce the misuse of humans and rationalize the costs. Nevertheless, this means to define a flexible and agile control system of the whole center, able to adapt to the various disturbances that could affect the system. Such control architecture have been extensively studied in the field of manufacturing [30], and their extension toward service companies still needs to be proved.

All the data produced by the centers, the logistics and the mail itself has to be analyzed in order to optimize maintenance and improve quality of service. Big data technologies are often used in order to analyze and combine data at an advanced and sophisticated level making it possible to give the big picture out of all collected data [31]. These technologies are highly used to improve customers' service by knowing their needs and expectations for future products or their feed-back after the use of a specific product in the market, which make the experience more beneficial to everyone. 
Future Human-machine interaction has different concepts in different logistic management processes. In fact, while humans' presence has high importance level in the strategic level because of their ability to make flexible decisions taking in consideration different parameters and changes the system could go through, in the operative level, the presence of humans could slow down the production process since repetitive and precise activities are better executed by robots [32]. However, at operational level, many interaction need to be established between humans and robots in order to benefit from the best abilities of both sides. The service orientation induced by Industry 4.0 is probably an interesting solution to enhance these interactions [33].

Finally, as the distribution chain, the number of items in each center and the number of actors involved are extremely large, it is necessary to develop the concept of digital twin which consists on creating a virtual model that realistically reflects the current system's state, this can efficiently predict the future behavior of the system and make decisions based on realistic data sets at a lower cost. [34]. The development of a digital twin at the level of the cyber-physical production system will give the ability to humans to make the best decisions more rapidly, gathering the maximum amount of data on the connected systems.

\section{Conclusions}

One of the challenges of the industry 4.0 is the involvement of the customer in the production experience. Humans are considered the heart of the fourth industrial revolution making the improvement of service experience an obligation no more an option. Future factories need flexible and reconfigurable control production systems that enable them to evaluate rapidly with market changes. Today, smart logistic companies need to bring more value to their customers by integrating multiple product use functions and associated services. The use of information and communication technologies is primordial for smart logistics 4.0, this facilitates the association of logistic and business management tools in order to synchronize logistics and production flows and implement a dynamic production planning. This work focused on the French postal service company La Poste. La Poste has the particularity of treating high volumes of mail and parcel items every day. A description of the global organization of La Poste and its sorting process from the collection to the distribution of mail items is presented here.

In this article, a literature review on different technologies used over the last decades in transportation, sorting and resource planning fields is presented in addition to future challenges in the same research axes needed to meet the requirements of the industry 4.0 .

\section{Bibliography}

1. Lu Y, Ju F (2017) Smart Manufacturing Systems based on Cyber-physical Manufacturing Services (CPMS). IFAC-Pap 50:15883-15889 
2. Droździel P, Wińska M, Madleňák R, Szumski P (2017) Optimization of the Post Logistics Network and Location of the Local Distribution Center in Selected Area of the Lublin Province. Procedia Eng 192:130-135

3. López JAV, Dueñas ABP, Ruiz RJL, Córdoba SM (2014) System Optimization Courier and Parcel in Cities. Procedia - Soc Behav Sci 160:577-586

4. Boloukian R, Siegmann J (2016) Urban Logistics; a Key for the Airport-Centric Development - A Review on Development Approaches and the Role of Urban Logistics in Comprehensive Airport-Centric Planning. Transp Res Procedia 12:800-811

5. Sim T, Lowe TJ, Thomas BW (2009) The stochastic p-hub center problem with service-level constraints. Comput Oper Res 36:3166-3177

6. Zäpfel G, Bögl M (2008) Multi-period vehicle routing and crew scheduling with outsourcing options. Int J Prod Econ 113:980-996

7. Niroomand I, Nsakanda AL (2018) Improving collection flows in a public postal network with contractor's obligation considerations. Int J Prod Econ 198:79-92

8. Chen C, Pan S (2015) Using the Crowd of Taxis to Last Mile Delivery in Ecommerce: a Methodological Research.

9. Clausen U, Geiger C, Pöting M (2016) Hands-on Testing of Last Mile Concepts. Transp Res Procedia 14:1533-1542

10. Devari A, Nikolaev AG, He Q (2017) Crowdsourcing the last mile delivery of online orders by exploiting the social networks of retail store customers. Transp Res Part E Logist Transp Rev 105:105-122

11. Cesar M, Shinghal R (1990) An algorithm for segmenting handwritten postal codes. Int J Man-Mach Stud 33:63-80

12. Ciresan DC, Meier U, Gambardella LM, Schmidhuber J (2010) Deep Big Simple Neural Nets Excel on Handwritten Digit Recognition. Neural Comput 22:3207-3220

13. Niu X-X, Suen CY (2012) A novel hybrid CNN-SVM classifier for recognizing handwritten digits. Pattern Recognit 45:1318-1325

14. Basu S, Das N, Sarkar R, Kundu M, Nasipuri M, Kumar Basu D (2010) A novel framework for automatic sorting of postal documents with multi-script address blocks. Pattern Recognit 43:3507-3521

15. Kamranian Z, Monadjemi SA, Nematbakhsh N (2013) A novel free format Persian/Arabic handwritten zip code recognition system. Comput Electr Eng 39:1970-1979

16. Basu S, Das N, Sarkar R, Kundu M, Nasipuri M, Kumar Basu D (2010) A novel framework for automatic sorting of postal documents with multi-script address blocks. Pattern Recognit 43:3507-3521

17. Srihari SN (1993) Recognition of handwritten and machine-printed text for postal address interpretation. Pattern Recognit Lett 14:291-302

18. Bard JF, Binici C, deSilva AH (2003) Staff scheduling at the United States Postal Service. Comput Oper Res 30:745-771 
19. Burns RN, Carter MW (1985) Work Force Size and Single Shift Schedules with Variable Demands. Manag Sci 31:599-607

20. Aykin T (1996) Optimal Shift Scheduling with Multiple Break Windows. Manage Sci 42:591-602

21. Emmons H (1985) Work-Force Scheduling with Cyclic Requirements and Constraints on Days Off, Weekends Off, and Work Stretch. IIE Trans 17:816

22. Júdice J, Martins P, Nunes J (2005) Workforce planning in a lotsizing mail processing problem. Comput Oper Res 32:3031-3058

23. Malhotra MK, Ritzman LP, Benton WC, Keong Leong G (1992) A model for scheduling postal distribution employees. Eur J Oper Res 58:374-385

24. Rabta B, Wankmüller C, Reiner G (2018) A drone fleet model for last-mile distribution in disaster relief operations. Int J Disaster Risk Reduct 28:107112

25. Zhang X, Yue S, Wang W (2006) The review of RFID applications in global postal and courier services. J China Univ Posts Telecommun 13:106-110

26. Barreto L, Amaral A, Pereira T (2017) Industry 4.0 implications in logistics: an overview. Procedia Manuf 13:1245-1252

27. Leitão P, Rodrigues N, Barbosa J, Turrin C, Pagani A (2015) Intelligent products: The grace experience. Control Eng Pract 42:95-105

28. Trentesaux D, Thomas A (2013) Product-Driven Control: Concept, Literature Review and Future Trends. In: Serv. Orientat. Holonic Multi Agent Manuf. Robot. Springer, pp 135-150

29. Chalfoun I, Kouiss K, Huyet A-L, Bouton N, Ray P (2013) Proposal for a Generic Model Dedicated to Reconfigurable and Agile Manufacturing Systems (RAMS). Procedia CIRP 7:485-490

30. Cardin O, Ounnar F, Thomas A, Trentesaux D (2017) Future Industrial Systems: Best Practices of the Intelligent Manufacturing and Services Systems (IMS2) French Research Group. IEEE Trans Ind Inform 13:704-713

31. Witkowski K (2017) Internet of Things, Big Data, Industry 4.0 - Innovative Solutions in Logistics and Supply Chains Management. Procedia Eng 182:763-769

32. Hofmann E, Rüsch M (2017) Industry 4.0 and the current status as well as future prospects on logistics. Comput Ind 89:23-34

33. García-Domínguez A, Marcos-Bárcena M, Medina-Bulo I, Prades-Martell L (2013) Towards an Integrated SOA-based Architecture for Interoperable and Responsive Manufacturing Systems. Procedia Eng 63:123-132

34. Uhlemann TH-J, Lehmann C, Steinhilper R (2017) The Digital Twin: Realizing the Cyber-Physical Production System for Industry 4.0. Procedia CIRP 61:335-340 